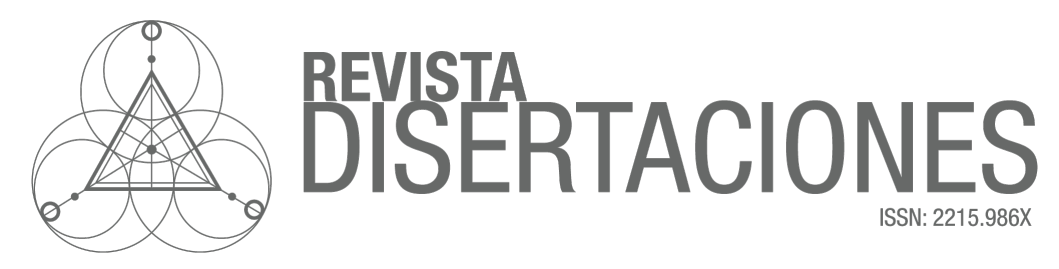

\title{
El marxismo de Jorge Veraza como una reconstrucción crítica de la teoría marxista
}

Jorge Veraza's Marxism as a Critical Reconstruction of Marxist Theory

\author{
David Valerio Miranda \\ Universidad Michoacana de San Nicolás de Hidalgo - México
}

$\Phi$

\section{Resumen}

El presente artículo pretende identificar la construcción teórico-crítica que el autor mexicano Jorge Veraza desarrolla para el concepto "marxismo", a partir de sus publicaciones en las que reflexiona la obra de Karl Marx. Mediante la revisión de su lectura a Marx, se ratifica que su construcción y significación conceptual marxista se enfoca en la crítica al sistema políticoeconómico capitalista actual. La aportación del presente texto, también consiste en analizar la obra del autor mexicano, con base en un concepto que funge como una crítica al capitalismo desde el contexto académico de México en las últimas tres décadas, considerando el impacto negativo para la tradición marxista que se desarrolló a partir de la caída del Muro de Berlín en 1989 y la disolución de la URSS en 1991.

Palabras clave: Marxismo, Crítica, Capitalismo, México.

\footnotetext{
"Recibido: 30 de junio de 2020. Aceptado: 14 de septiembe de 2020.

Contacto: dvaleriomiranda@gmail.com
} 


\title{
David Valerio Miranda
}

\begin{abstract}
This article aims to identify the theoretical-critical construction that the Mexican author Jorge Veraza develops for the concept of "Marxism", based on his publications in which he reflects on the work of Karl Marx. By reviewing his reading of Marx, it is ratified that its construction and Marxist conceptual significance focuses on the criticism of the current capitalist politicaleconomic system. The contribution of this text also consists in the analysis the work of the Mexican author, based on a concept that serves as a critique of capitalism from the academic context of Mexico in the last three decades, considering the negative impact on the Marxist tradition developed after the fall of the Berlin Wall in 1989 and the dissolution of the USSR in 1991.
\end{abstract}

Keywords: Marxism, Criticism, Capitalism, Mexico.

\section{(C) (i) () $\bigcirc$}

Material publicado de acuerdo con los términos de la licencia Creative Commons AttributionNonCommercial-NoDerivatives 4.0 International (CC BY-NC-ND 4.0). Usted es libre de copiar o redistribuir el material en cualquier medio o formato, siempre y cuando dé los créditos apropiadamente, no lo haga con fines comerciales y no realice obras derivadas. 
El marxismo de Jorge Veraza como una

reconstrucción crítica de la teoría marxista

\section{Introducción}

México no se queda atrás en cuanto a producir una gran variedad de interpretaciones para el concepto marxismo. Discusiones de personajes como: Vicente Lombardo Toledano, Eli de Gortari, Adolfo Sánchez Vázquez, José Revueltas, Bolívar Echeverría, Enrique Dussel, Armando Bartra, Carlos Illades, Jaime Ortega, Carlos Pereyra, y Jorge Veraza son solo unos de los tantos posibles.'

Gran variedad de autores, que ya sea, desde el ámbito académico, universitario o la militancia política, debatieron e interpretaron la obra de Marx, para realizar un examen al capitalismo desde la circunstancia del país azteca. Sin embargo, para la presente comunicación solo se considera al autor Jorge Veraza, con el fin de ofrecer un panorama de lo que entiende este por marxismo, mismo concepto que usa para realizar una crítica al capitalismo desde el contexto del México actual de las últimas tres décadas.

Jorge Veraza Urtuzuástegui (1951) es un docente investigador mexicano adscrito a la Universidad Autónoma Metropolitana, campus Iztapalapa (UAM-I), Ciudad de México, quien se ha dedicado por décadas al estudio del pensamiento teórico de Marx. Sus investigaciones han mantenido un diálogo con importantes marxistas mexicanos, como Bolívar Echeverría ${ }^{2}$ a quien constantemente cita y discute en diferentes momentos de su obra, o Enrique Dussel ${ }^{3}$ al que de igual manera considera, debate y coincide con algunas

\footnotetext{
${ }^{1}$ Para profundizar sobre las diferentes generaciones de pensadores marxistas en México consultar: Illades, Carlos. Camaradas, Nueva historia del comunismo en México. México: FCE, 2017, y El Marxismo En México. Una Historia Intelectual. México: Taurus, 2018. Carr, Barry. La izquierda mexicana a través del siglo XX. México: Era, 1996. Y Cocheiro Bórquez, Elvira, et al. Antología del pensamiento crítico mexicano contemporáneo. Buenos Aires: CLACSO, 2015.

${ }^{2}$ En Leer el capital... (2007 34), Veraza respalda y utiliza el concepto de Bolívar Echeverría de "Modernidad Capitalista".

${ }^{3}$ También en Leer el capital..., Veraza le discute a Dussel la idea de filosofía en Marx, cuestión que Dussel expone en El último Marx (1990)
} 


\section{David Valerio Miranda}

de sus posturas. Qué decir de Adolfo Sánchez Vázquez al que con frecuencia recurre en sus obras; también está Jaime Ortega, quien en algunos de sus artículos coincide con Veraza citándolo. En suma, Veraza es un pensador vigente en las discusiones académicas del marxismo en México en los últimos años.

En su texto Dialéctica histórica de la superación de la crisis del marxismo, admite haber realizado profundas investigaciones para la construcción del concepto de interés, así lo escribe: "ya hace décadas he estado laborando en la reconstrucción del marxismo, tarea que en el siglo XXI se ha vuelto urgente" (Veraza 2015 216). Confirmando que no sólo ha estudiado al filósofo alemán, sino que justifica dicho trabajo como importante, ${ }^{6}$ por ello, mediante el análisis de algunas de sus publicaciones se pretende identificar su interpretación del concepto marxismo, pues dicha construcción mantiene un carácter analítico frente al sistema político-económico actual.

El trabajo crítico respecto a la teoría marxista por parte de Jorge Veraza, se refleja en distintas publicaciones, especialmente en aquellas en donde debate las obras del filósofo germano como las siguientes: Leer nuestro tiempo. Leer el Manifiesto. A 150 años de la publicación del Manifiesto del Partido Comunista (1998), Para pensar la opresión y la emancipación desde la posmodernidad. Crítica a la dialéctica del amo y el esclavo en Hegel (2005), Leer el capital hoy (2007), Los manuscritos de 1844. Un discurso revolucionario integral de cómo los escribió Marx y cómo leerlos para la reconstrucción del marxismo en el siglo XXI (2011), incluimos también la entrevista que le realizó Manuel del Pino, titulada: La degradación civilizatoria y las tareas del marxismo.

\footnotetext{
${ }^{4}$ En Leer nuestro tiempo, leer el manifiesto... 2013, Veraza expresa que coincide con Adolfo Sánchez Vázquez, específicamente en su libro: Entre la realidad y la utopía, 1999, en el sentido que las utopías socialistas no terminan con el fracaso de la URSS, p 49. También ha interpretado el libro: Etica y política (2010).

"Jaime Ortega, en su artículo: "El valor de uso en el marxismo de Bolívar Echeverría", sostiene estar de acuerdo con el desarrollo de la noción de "Valor de uso", que se presenta en una publicación de Veraza: Lectura de El capital de Bolívar Echeverría (2011). También, en su artículo: "No cae rayo en cielo sereno: dos episodios del marxismo en México" (2016). Ortega sostiene que, Veraza con sus investigaciones realiza una importante aportación a la tradición del marxismo en México.

${ }^{6}$ La importancia de seguir estudiando a Marx, reside en que actualmente sigue siendo necesaria una crítica al capitalismo, por su pragmatismo falto de ética, para profundizar sobre las actuales deficiencias éticas del capitalismo consultar: Novoa Portela, María Pastora. Crisis económica, cuestionamiento ético al capital. México: UAM, 2017.
} 
El marxismo de Jorge Veraza como una

reconstrucción crítica de la teoría marxista

Junto a la entrevista, viene un texto de Veraza que se titula: "Dialéctica histórica de la superación de la crisis del marxismo", el cual también se considera. Estos dos, publicados en: Marxistas de hoy (2015). ${ }^{7}$

Por último, consideramos la conferencia magistral: Marx y el marxismo del siglo XXI, exposición que Jorge Veraza realizó en la Feria Internacional del Libro del Palacio de Minería (FILPM) 2019. Acto, donde explicó ideas que aportan a la compresión de su interpretación y construcción del concepto "marxismo" como crítica al capitalismo desde el academicismo en México.

De las obras usadas, cronológicamente el texto más antiguo se publicó en el año de 1998, y cuenta con una primera reimpresión en 2013. La metodología de revisar primero la obra más lejana hasta la más reciente, es para detectar, si existe una evolución o consecución en la significación del concepto de interés, desde la temporalidad de las mismas. De esta forma, ratificamos que el objetivo es detectar la significación que Jorge Veraza le da al concepto marxismo desde la teorización académica. Al mismo tiempo, este escrito pretende someterlo a un análisis crítico en el que se marque una postura personal respecto a la interpretación de Veraza, con esto, también se aporta a la amplia discusión sobre el marxismo en México.

En suma, las características y temáticas que se discuten y analizan en el presente texto, aportan un panorama general de lo que entiende Jorge Veraza por "marxismo como crítica al capitalismo", pues al revisar sus principales ideas permiten identificar dicha propuesta teórica desde su lectura, recepción e interpretación en México.

A partir del análisis de Veraza y su intento de actualizar a Marx, se reconstruye el concepto "marxismo" desde el contexto mexicano y, por tanto, latinoamericano. Reconstrucción que por toda la amplitud de debates y temáticas con las que se enlaza, se puede sostener que es una crítica al capitalismo actual. Con esto, se resalta que en la actualidad es importante seguir construyendo el marxismo como una necesaria, vigente y

\footnotetext{
${ }^{7}$ Cabe destacar, que para el presente ensayo no se utilizan las obras de Jorge Veraza en su totalidad, sino como en los párrafos se explica, se consideran solo aquellas en las que interpreta la obra directa de Marx, así mediante este ejercicio, Veraza construye una interpretación propia del concepto, dentro de la gran variedad de interpretaciones ya existentes.
} 


\section{David Valerio Miranda}

legítima crítica al capitalismo, cuando menos desde la academia, para desde este ámbito generar contrapesos, que ayuden en la edificación de sociedades humanas más justas.

El concepto marxismo en Leer nuestro tiempo, leer el Manifiesto. A 150 años de publicación del Manifiesto del Partido Comunista

Casi desde el inicio de esta obra Veraza escribe que la revolución bolchevique y por lo tanto la URSS, no fueron socialistas, mucho menos marxistas o comunistas. Sostiene que las intenciones de construir el socialismo duraron de 1917 hasta 1924 con la muerte de Lenin. Señala que el problema de identificar el experimento soviético como marxistas o socialista, da pie a pensar en desechar dichos proyectos a partir de la caída del Muro de Berlín (Cf. Veraza 2013 11-15).

Muestra una preocupación por deslindar su concepto de marxismo o lo que él entiende por éste, de los experimentos político-económicos del siglo XX denominados como "socialismo realmente existente". A partir de ahí, descarta lo que no identifica como marxismo.

Asimismo pretende debatir con las viejas visiones neoliberales; pero, que aún perduran y sostienen que el socialismo, y por lo tanto, el marxismo son una amenaza para la "libertad", pues la aplicación de sus proyectos necesariamente derivan en dictaduras totalitarias. Visiones como la de Friedrich Hayek, ${ }^{8}$ Karl Popper ${ }^{9}$ o Milton Friedman. ${ }^{10}$ De esta manera, Veraza sostiene que distanciando al marxismo del "socialismo real" se abre la posibilidad de superar estas críticas.

Respecto al contexto mexicano considera el caso del levantamiento zapatista $(E Z L N)^{11}$ en $1994 .^{12}$ Al inicio no relaciona el concepto marxismo con el zapatismo de

\footnotetext{
${ }^{8}$ Consultar: Hayek, Friedrich. Camino de servidumbre. Madrid: Alianza. 2009.

${ }^{9}$ Consultar: Popper, Karl. La sociedad abierta y sus enemigos. Barcelona: Paidós, 2006.

${ }^{10}$ Friedman Milton, Rose Milton. Libertad de elegir, hacía un nuevo liberalismo económico. España: Grijalbo, 1980.

${ }^{11}$ Entiéndase las siglas EZLN: Ejercito Zapatista de Liberación Nacional.
} 
El marxismo de Jorge Veraza como una

reconstrucción crítica de la teoría marxista

manera muy clara, debido a las distintas interpretaciones que ha habido de lo primero. Por ejemplo, una visión que estaría en desacuerdo con el zapatismo sería la "leninista", por cuestiones como la vanguardia del partido, y la toma del poder, mientras los zapatistas se definen como pluralistas y pugnan contra el poder (Cf. EZLN Sexta 2005).

En la cuestión anterior Veraza balancea la relación marxismo y zapatismo, asumiendo como falso, el rompimiento del zapatismo con todos los esquemas de la tradición de izquierda. Por ejemplo, el consejismo que propone Rosa Luxemburgo ${ }^{13}$ y que es más cercano al proyectado por Marx en La Comuna de París. Práctica que está presente en el zapatismo, rompiendo así con el estalinismo que "según Rosa Luxemburgo (la revolución) $)^{14}$ también la ensalzará. El consejismo insiste en el desarrollo de la revolución antes de la toma del poder y en otra forma de hacer política y otro tipo de político". (Veraza 2013 36).

Veraza también sostiene, que hay interpretaciones deficientes, por ejemplo, expone que la posmodernidad identifica al marxismo como una "religiosidad sectaria". El autor rechaza esta interpretación y propone la superación de este tipo de ideologización cuando afirma que "hay que combatir las ideologías de las clases dominantes y entre ellas la ideologización del marxismo. Es decir, el falseamiento del pensamiento de Marx por la recepción que de él hace la ideología dominante y que lo desestructura o deforma" (Veraza 2013 17).

Al igual que en la teoría marxista, uno de los conceptos centrales a tratar por Veraza es el de proletariado. Sin embargo, en el caso del pensador mexicano tenemos un proletariado "ampliado" puesto que identifica a las minorías y grupos oprimidos como la comunidad LGBT, mujeres y etnias, entre otros, como parte del proletariado. Para Veraza, la desigualdad, la falta de reconocimiento de derechos y la discriminación hace que estos grupos no estén exentos de formar parte del proletariado, por el contrario, se proletarizan y, por lo mismo, pasan a ser parte de una clase revolucionaria diversa. Con

\footnotetext{
${ }^{12}$ Para profundizar sobre el levantamiento zapatista en México de 1994, consultar: Escalante Gonzalbo, Pablo, et al, Nueva historia mínima de México. México: COLMEX, 2012.

${ }^{13}$ Consultar: Luxemburgo, Rosa. Huelga de masas, partido y sindicato. Madrid: Fundación Federico Engels, 2010.

${ }^{14}$ El paréntesis es mío.
} 
esto admite que el proletariado no es la única clase revolucionaria, apoyándose en Marx y Engels quiénes lo suscriben en el mismo Manifiesto (Cf. Veraza 2013 46). ${ }^{15}$

Una cuestión más respecto al marxismo y las mujeres en esta obra, es la del feminismo. El autor basándose en el Manifiesto, analiza e interpreta que tanto el marxismo como el feminismo coinciden en su planteamiento revolucionario, pues pugnan por abolir la opresión y la desigualdad entre géneros, es decir, el marxismo promueve la liberación de la mujer, del hombre y de toda la humanidad en conjunto que es oprimida por el capitalismo. A partir de las afirmaciones anteriores, se delimita su interpretación de marxismo, por ejemplo, identificandola como pluralista.

La democracia también cabe en su análisis, comúnmente se establece un rechazo y diferenciación entre democracia y marxismo. Frente a esto, Veraza propone que, según la interpretación en cuestión, también hay puntos de traslape entre ambas propuestas. Aquí está pensando en una cuestión que ya hemos planteado, es decir, en las democracias consejistas horizontales más cercanas al consejismo obrero propuesto por Marx (Comuna de París) y Rosa Luxemburgo, sosteniendo que se debe: "trascender de la democracia burguesa hacia la democracia proletaria comunista" (Veraza 2013 77).

Por último, la problemática entre Filosofía y Marxismo es considerada por Veraza según la interpretación en la que Marx abandona o supera la Filosofía, desde La ideología alemana. ${ }^{16}$ También cita pasajes directos de Marx, concretamente, de la Introducción a la crítica de la filosofía del derecho de Hegel, ${ }^{17}$ obra en la que Marx considera importante el que la filosofía llegue a los oprimidos para la realización de la revolución y su consecuente liberación (Cf. Veraza 2013 75).

\footnotetext{
${ }^{15}$ Consultar: Marx Carlos, Engels Federico. Manifiesto del Partido Comunista. Madrid: Mestas, 2007.

${ }^{16}$ Consultar: Marx Carlos, Engels Federico. La ideología alemana. Barcelona: Grijalbo, 1974.

${ }^{17}$ Consultar: Marx Carlos. Introducción a la crítica de la filosofía del derecho de Hegel. Madrid: Biblioteca Nueva, 2010. 
El marxismo de Jorge Veraza como una

reconstrucción crítica de la teoría marxista

El concepto marxismo en Para pensar la opresión y la emancipación desde la posmodernidad. Crítica a la dialéctica del amo y el esclavo en Hegel

Esta obra de Jorge Veraza que data de 2005 desarrolla la problemática del amo y el esclavo en Hegel. ${ }^{18}$ Después de leer el título, se podría pensar que no hay mucho que pueda aportar a la construcción y comprensión del concepto marxismo; no obstante, la publicación resulta ser importante para nuestro análisis.

Veraza compara la dialéctica hegeliana del amo y el esclavo, con lo que para él sería la interpretación dialéctica de Marx. Afirma que la propuesta de Hegel es un tanto más pasiva, por la sintonía e interdependencia a través del trabajo entre el amo y el esclavo, misma que se sustenta en el temor de ambos a la muerte.

Una dialéctica que recae un tanto en el nihilismo, interpretación que es bien acogida por la tendencia posmoderna. En esta lectura de la dialéctica hegeliana, además del temor a la muerte tanto del amo como del esclavo, está de por medio la dependencia del trabajo, descartando el progreso, al tratar de encontrar respuestas en lo místico, lo metafísico que escapa a la compresión humana desde temáticas como dios o la muerte. Interpretación sumisa que fácilmente deviene en la irresponsabilidad del nihilismo, al quedarse en la mera abstracción.

Respecto a la dialéctica de marxista, Veraza sostiene que "para Marx, la realización de la libertad del hombre a través del trabajo ocurre mediante el trabajo revolucionario social -el más propio de la especie- y que conduzca a la autoliberación de la última clase explotada, el proletariado, y a la construcción de la sociedad comunista luego de destruir/negar a la sociedad burguesa" (Veraza, 2005: 147).

Una propuesta del marxismo, es exhortar al oprimido a su liberación mediante el trabajo revolucionario que niega al capitalismo. A diferencia de las interpretaciones de la dialéctica hegeliana donde el sometido se enajena al amo a partir del trabajo, sustentándose así un lazo entre ambos basado en el temor a la muerte, siendo esta de cualquier forma inevitable.

\footnotetext{
${ }^{18}$ Para profundizar, consultar: Hegel. El señor y el siervo, en Fenomenología del espíritu. México, FCE, 2012. Ver páginas 117-119.
} 


\section{David Valerio Miranda}

De esta manera, en la propuesta de Hegel y la interpretación posmoderna no parece haber salida, al depender tanto el esclavo del amo como el amo del esclavo por el temor a morir, no hay progreso pues el nihilismo es lo que queda. En el marxismo la dialéctica es progresista, pues busca liberar o más bien la autoliberación de los oprimidos que mediante su afirmación niegan el orden capitalista, y por ello, es dialéctica.

Este afán liberador y revolucionario del marxismo, se entiende como una de sus características, misma que no se presentan como pasiva, ya que, "La violencia revolucionaria está justificada por sus metas y por sus premisas en vista de sepultar definitivamente la dialéctica del amo y el esclavo" (Veraza 2005 154).

Desde lo anterior, el marxismo en la interpretación de Veraza, también se caracteriza por buscar superar la dialéctica del amo y el esclavo como se da en la interpretación de Hegel. En la actualidad diríamos que también la lectura nihilista posmoderna, a cambio de una dialéctica revolucionaria que busque el progreso mediante la liberación de los oprimidos por sí mismos, es decir, un marxismo que sigue siendo una de las principales críticas al capitalismo, aún en el siglo XXI, al respaldar que existe una meta que alcanzar, progreso y tiempo para mejorar. Posición que sigue relacionando de manera indisoluble lo teórico con lo praxiológico.

\section{El concepto marxismo en Leer El capital hoy}

Al igual que en su libro "Leer el Manifiesto hoy...", casi en el comienzo del texto, empieza hablando de una crisis del marxismo, que se ha desarrollado a partir de la implosión de la URSS. Crisis que según él se subsana un poco con el levantamiento zapatista de 1994 en México (Cf. Veraza 2007 13).

Sin embargo, aporta otros elementos en este libro, por ejemplo, sostiene que: "En el prólogo a la primera edición de El capital, ${ }^{19}$ Marx dice que el objetivo último de su obra es sacar a la luz la ley económica que rige el movimiento de la sociedad moderna. Marx utiliza como sinónimos sociedad moderna, sociedad capitalista o sociedad burguesa" (Veraza 2007 34).

\footnotetext{
${ }^{19}$ Consultar: Marx, Carlos. El capital I: crítica de la economía política. México: FCE, 2012.
} 
El marxismo de Jorge Veraza como una reconstrucción crítica de la teoría marxista

Lo anterior brinda otro elemento para nuestro discernimiento sobre lo que Veraza entiende por marxismo, basándose en "El capitap". Ya que interpreta, las características y objetivos de la obra, que de esta manera muestran la propuesta de Marx o del marxismo. Ideas que pretenden analizar y desenmascarar la función económica, política, social y cultural de la sociedad capitalista, para así buscar su superación.

Resalta también la cuestión del partido, proponiendo que el marxismo no sostiene una tesis en la que se base un monopolio partidista, apoyándose en la Carta de Marx a Freiligrath (1860) sostiene lo siguiente: "La idea de Marx sobre la organización y el partido tiene un contenido histórico complejo, no es una idea meramente funcional en la que un partido monopoliza y tiene la verdad. La verdad resulta dialécticamente de la discusión y la confrontación con todas las corrientes" (Veraza 2007 184). Lo anterior de nuevo enfatiza que el marxismo de Veraza considera una representación pluralista, consejista y horizontal.

El concepto marxismo en Leer los Manuscritos de 1844: un discurso revolucionario integral de cómo los escribió Marx y cómo leerlos en el siglo XXI

Al igual que en sus libros anteriores, Veraza insiste en la importancia de volver al estudio de las obras de Marx para comprender el presente, en este caso los Manuscritos de $1844 .^{20}$ Considera que estos también pueden ayudar al análisis de las sociedades contemporáneas, con sus fenómenos y problemas.

Realiza un recuento de la historia reciente del marxismo, y habla desde los inicios de la crisis de los setenta, pasando por 1989 (caída del Muro de Berlín) y 1991 (disolución de la URSS), así como un relativo resurgimiento en 1994 (Insurrección zapatista) y la necesidad de una crítica revolucionaria integral, sostenida por los marxistas en la actualidad. Más adelante, vuelve a hacer énfasis en el levantamiento zapatista, como un renacimiento del marxismo (Cf. Veraza 2011).

\footnotetext{
${ }^{20}$ Consultar: Marx, Carlos. Manuscritos económicos -filosóficos de 1844. México: Grijalbo, 1974.
} 


\section{David Valerio Miranda}

Lo novedoso en esta publicación, es el concepto "integral" o más bien el "análisis integral", al cual refiere como un estudio profundo en el que se engloban diferentes aspectos como el político, el económico, el social, el cultural, es decir, el contexto histórico. Mediante este examen crítico, se reafirma la necesidad de pensar y realizar la superación del capitalismo, planteando preguntas como: ¿Qué sigue después de este proyecto fallido de cultura? O como diría Bolívar Echeverría, ¿Qué sigue de esta modernidad capitalista fallida. ${ }^{21}$

Veraza considera que "el movimiento práctico altermundista, antiglobalización neoliberal, antiimperialista y anticapitalista ha seguido creciendo y, a la par, su necesidad de desarrollo teórico lo lleva a recuperar cada vez con mayor amplitud y profundidad al marxismo, en particular el estudio de la obra de Karl Marx" (Veraza, 2011).

Aceptar el fracaso de las actuales sociedades y el capitalismo (sobre todo después de la crisis mundial de 2008), exhibe la necesidad de cambio. Evidencia la intención de superación que apunta otra vez hacia los estudios teóricos de Marx, pues "para Marx la praxis - es decir la práctica humana entendida en un sentido integral- es la clave que permite explicar la historia puesto que también la produce" (Veraza 2011).

En el análisis crítico del contexto de nuestras sociedades, es donde cabe la posibilidad de encontrar respuestas a las incertidumbres y problemáticas actuales. Según Veraza Los Manuscritos de 1844 de Marx son ejemplo de este tipo de estudio, y he ahí la importancia de la obra en la actualidad.

Lo anterior aporta la reafirmación del carácter crítico de este marxismo, que se emite a partir del examen de las sociedades en sentido amplio, donde se ligan aspectos como la cuestión económica que Veraza, siguiendo Marx, sostiene es la base de la explotación capitalista, el injusto despojo material: "Marx pasa luego a insistir en que, ante la enajenación material de las necesidades, la superación de la misma es obligadamente una "acción comunista real", no sólo política sino social y cotidiana" (Veraza 2011).

Así, el analizar el contexto histórico, político, económico, social cotidiano, etcétera; es una acción comunista, pues el análisis se puede equiparar con el concepto marxista, ya que, consiste en examinar las sociedades capitalistas para buscar su superación.

\footnotetext{
${ }^{21}$ Consultar: Echeverría, Bolívar. Las ilusiones de la modernidad. México: UNAM/El equilibrista, 1995.
} 
El marxismo de Jorge Veraza como una

reconstrucción crítica de la teoría marxista

Veraza lo ejemplifica para invitar a la lectura de los Manuscritos económico-filosóficos de Marx, siendo este uno de los principales objetivos de su libro.

El concepto marxismo en la entrevista Marxistas de hoy: la degradación civilizatoria y las tareas del marxismo

Veraza concedió una entrevista a Manuel del Pino en 2015, la cual se publicó en la revista "Desde abajo". El testimonio permite observar algunos elementos para la revisión crítica marxista que el autor propone al hablar de marxismo. La entrevista comienza con la pregunta: “¿Cómo llegó al marxismo?" y Veraza responde que fue a muy temprana edad, pues varios miembros de su familia simpatizaban con el marxismo y el socialismo. A los quince años llegó a él la lectura del Manifiesto, y en el bachillerato recibió una clase sobre El capital, impartida por Bolívar Echeverría (Cf. Del Pino 2015 177-180).

Después, se le cuestiona como relaciona al "marxismo" con Latinoamérica, Veraza responde que se considera influido por la Revolución cubana de la que tuvo conocimiento cuando era muy joven, la revolución le dio esperanza. Más adelante, en 1999 defendió su tesis doctoral en Estudios Latinoamericanos titulada: "Estudios de Marx sobre Latinoamérica" (Cf. Del Pino 2015 190).

En el mismo número que se publica esta entrevista, acompaña un texto que apoya esta relación entre marxismo y Latinoamérica al sostener que las lecturas e interpretaciones del "marxismo" en dicha región han sido bien estudiadas, incluso se ha pretendido una adaptación y aplicación de estas. En efecto, señala que "América Latina está siendo la cuna no sólo de importantes movimientos sociales sino desde hace más de dos décadas también del mejor marxismo" (Veraza 2015 221).

Cuando se le pregunta si el pensamiento de Marx se encuentra en crisis, el investigador mexicano contesta:

Desde 1983 - a 100 años de la muerte de Marx - se volvió evidente también de un modo histórico y teórico- que la crisis del marxismo no es crisis del pensamiento de 


\section{David Valerio Miranda}

Marx sino del de los marxistas. Así que la primera tarea de la teoría marxista hoy es la de establecer la diferencia crítica entre ambos, así como la especificidad de Marx; incluidas las consecuencias para su aplicación a la realidad contemporánea" (Del Pino 2015 195).

Desde lo anterior, designa como válida una diferenciación que distinga a Marx del "marxismo" y "los marxistas". Proponiendo con esto, una importante dilucidación que permita identificar errores de interpretación,

Análogo error vimos cuando se postuló a Trotsky, a Mao y más adelante, a Gramsci o a Rosa Luxemburgo etc., para cumplir tal función de dominio ideológico. Autores que unos más y otros menos, nos entregan aportes importantes al marxismo, por supuesto; pero eso no debe ser usado como pretexto para someter el pensamiento de Marx a sus respectivas perspectivas (Del Pino 2015 200).

Asimismo, en el texto: "Dialéctica histórica de la superación de la crisis del marxismo", Veraza reafirma que "la crisis del marxismo es la crisis de los marxistas pero de ninguna manera es la crisis del pensamiento de Marx" (Veraza 2015 209-210).

Lo anterior puede resultar un tanto complicado, sin embargo, Veraza lo toma en cuenta e intenta solucionar la disyuntiva proponiendo lo siguiente:

El verdadero Sol del desarrollo y reconstrucción del marxismo es el pensamiento de Marx; y los posteriores marxistas podremos aportar algo al marxismo y aún desarrollarlo si forjamos nuestras ideas con arreglo a las de Marx, asumidas en forma consecuente e integral [...] de esta manera el principio reconstructivo y de desarrollo del marxismo es simultáneamente un principio generoso de acogida de cualquier aporte auténtico. Y según esta misma norma, tenemos que el marxismo que así se reconstruye y se desarrolla es un marxismo no sectario porque no excluye a este o aquel marxista dígase consejista, analítico, maoísta o trotskista, leninista, luxemburguista, frankfurhiano, autonomista (Veraza 2015 212).

Enfatiza diciendo que "se trata de un marxismo no dogmático pues se atiene a la cientificidad de la racionalidad dialéctica y todo aporte lo contrasta polémicamente tanto con la realidad como con la estructura integral del discurso crítico de Marx" (Veraza 2015 213). En este sentido se considera al "marxismo" como dialéctico, pues mantiene 
El marxismo de Jorge Veraza como una

reconstrucción crítica de la teoría marxista

como base el pensamiento y obra de Marx, pero a su vez, abierto a aportaciones constructivas. Así, resalta que las características de la propuesta marxista de hoy es que está fluyendo en una constante reconstrucción dialéctica. Según Veraza, esto se lograría por medio de "la reconstrucción del marxismo hoy; reconstrucción que debe ser la de un marxismo sin dogma y actuante" (Veraza 2015 228).

Finaliza el texto resaltando una vez más que el "marxismo", nada tuvo que ver con la URSS; pero que la derecha política del capitalismo neoliberal ha propiciado la identificación de Marx y del marxismo, con el "socialismo real", degradando y entorpeciendo un acercamiento crítico.

El concepto "marxismo" en la conferencia magistral: Marx y el marxismo del siglo XXI

Para finalizar este ensayo consideramos por último la conferencia magistral: Marx y el marxismo en el siglo XXI, impartida por Jorge Veraza en la Feria Internacional del Libro Minería (FILM) edición 2019, en la Ciudad de México. Ocasión en la que expuso varias ideas que aportan a la reafirmación de su construcción e interpretación crítica del marxismo. La conferencia se encuentra en línea, y por la temática que aborda, consideramos que es una buena antesala a las conclusiones generales.

Lo anterior, se respalda si consideramos que sostiene ideas como las diversas crisis que ha soportado el marxismo desde el siglo XIX; afirmando que la primera crisis del marxismo fue en 1896, con el revisionismo del social demócrata de Eduard Bernstein. Asimismo, asevera que durante el siglo $\mathrm{XX}$, ha habido una serie de crisis $\mathrm{y}$ renacimientos del marxismo, la última de estas crisis que califica como "catastrófica" se dio con la caída del Muro de Berlín y el desmembramiento de la URSS, ya que la URSS se asociaba con el socialismo y el socialismo se identificaba con el marxismo (Cf. Veraza 2019).

A partir de lo anterior, se tachó al marxismo de utópico, al designarse como una serie de "buenos deseos" mal planteados. Sin embargo, Veraza sostiene que no es lo mismo Karl Marx o sus ideas, a las diferentes interpretaciones que se denominan como 
"marxismo" o bien a los "marxismos". Prosigue exponiendo que, en 2008 se desarrolló la segunda gran crisis capitalista (la primera se dio de 1971 a 1982) sin embargo, hay que aclarar que esto no implica una crisis del capitalismo, sino que el capitalismo tiene una crisis, más no está en crisis (Cf. Veraza 2019).

El capitalismo se preserva mediante las crisis, pues la crisis es efecto y no causa de la explotación, a la cual se añaden otras crisis como la de salud, el hambre y la opresión. Cuestión que fue expuesta por Marx, por lo que, a partir de la crisis de 2008, se da un nuevo renacimiento con la popular afirmación: "Marx tenía razón" (Cf. Veraza 2019).

Según Veraza, se debe estudiar el pensamiento de Marx si se quiere entender el contexto capitalista actual, puesto que el filósofo decimonónico teorizó sobre el futuro, que es nuestro presente y que para Veraza es la misma época (2019).

Durante la conferencia, sigue afirmando que si bien el pensamiento marxista ha estado en crisis, el pensamiento de Marx no, por lo tanto, Marx es vigente en el presente. Para Veraza, es una falacia adjudicar las crisis del Marxismo al pensamiento de Marx. Incluso, enfatiza que el proyecto de Hugo Chávez en Venezuela no es marxista, ni el de Evo Morales en Bolivia (Cf. Veraza 2019).

En su exposición, toca el tema del marxismo y la cultura, afirmando que en el siglo XX Gramsci y la Escuela de Frankfurt propusieron que la cuestión de las contradicciones económicas no era primordial para la revolución. Según Veraza, estas interpretaciones le daban más peso a las contradicciones culturales. En las últimas décadas, se ha asociado el pensamiento de Marx a un marxismo cultural, que se asocia a las ideologías de género, al feminismo y los movimientos LGBT como una estrategia de desprestigiar y rechazar las teorías de Marx (Cf. Veraza 2019).

También sostiene que China no es un socialismo de mercado sino claramente un capitalismo. Sin embargo, los chinos se asocian al marxismo de manera demagógica, sólo para enfrentarse a otra potencia capitalista como lo es EEUU. El marxismo, al servicio de un estado capitalista totalitario es desfigurado, torcido, alejado de la teoría autentica de Marx y la consciencia revolucionaria (Cf. Veraza 2019). 
El marxismo de Jorge Veraza como una

reconstrucción crítica de la teoría marxista

En el caso de México, AMLO ${ }^{22}$ nada tiene que ver ni con Hugo Chávez y Venezuela, y mucho menos con el marxismo. Y concluye su conferencia, sosteniendo que es peligroso que la misma izquierda distorsione el pensamiento de Marx, finaliza diciendo que en los años presentes y venideros existe una importante necesidad de rescatar el pensamiento de Marx para realizar la necesaria crítica al capitalismo de hoy (Cf. Veraza 2019).

\section{Conclusiones}

Al hablar de la construcción intelectual del concepto marxismo de Jorge Veraza se habla de una reestructuración crítica, teórica y práctica de la teoría marxista que incluye diversos elementos de operación, reconocimiento del proletariado y diversos marxismos entre otros que enumero acontinuación

Operación enfocada hacia el consejismo y la horizontalidad, propuesta en la que se desechan las propuestas de tipo soviéticas, como el "partido único" y la estructura vertical de este. Para ejemplificarla, sin embargo, recurre a ejemplos problemáticos como el EZLN en México. Movimiento social, que se ha autodenominado como antisistémico, anti-capitalista y con una organización comunitaria de tipo consejista; no obstante, nunca se han pronunciado como una organización marxista, tampoco se han tomado una postura contraria. El ejemplo, quizá sirve para identificar la propuesta de Veraza, como un marxismo consejista, comunitario y plural.

Aunado a lo anterior, sostiene el reconocimiento de un proletariado "nuevo" o plural. Afirmando que en el siglo XXI las masas oprimidas no pertenecen homogéneamente a una clase determinada. Exponiendo así, que el marxismo de hoy puede ser un instrumento crítico ya no solo de la clase proletaria, sino de las amplias masas de

\footnotetext{
${ }^{22}$ Aquí, Veraza se refiere al nuevo gobierno de México, encabezado por Andrés Manuel López Obrador (AMLO). Administración que entró en vigor tras los comicios de 2018 y que se presentó con una retórica de "izquierda".
} 
oprimidos que se han diversificado pero coinciden y se identifican en padecer los males sociales del capitalismo como lo son la explotación, la exclusión, la desigualdad, entre otros.

Veraza apunta a reconocer los diversos "marxismos" que son distintos a la teoría filosófica del autor Karl Marx. Con esto, pretende destacar la propuesta originaría de Marx, de posteriores interpretaciones y aportaciones críticas al desarrollo y crecimiento de dicha teoría. Sin olvidar, o prevenir que en este devenir existe el constante riesgo de la deformación y ideologización de la teoría de Marx, problemática a la que los marxistas críticos del presente deben mantenerse atentos.

A partir de esto, propone una lectura dialéctica entre amo/esclavo que vaya hacia la liberación (dialéctica marxista), lectura que considera vigente la superación dialéctica entre opresores/oprimidos, despojándola de la interpretación nihilista posmoderna que no admite una alternativa a dicho binomio. Para Veraza, la esperanza aún debe germinar en los desposeídos para que busquen la superación de su condición precaria mediante la autoliberación. Propone también un marxismo que desenmascare al capitalismo, insiste en que no se olvide este "verdadero" propósito, que aunque el capitalismo es distinto en sus fases y crisis, la teoría marxista sigue vigente para estudiarlo y abolirlo. En este sentido tampoco debe olvidarse que el marxismo es de carácter revolucionario.

Sostiene que es importante, tener conciencia de las distintas "crisis marxistas", que se exploran en ejemplos históricos concretos como el stalinismo, la caída del Muro de Berlín y el fin de la URSS. El autor también resalta otros procesos como las distintas revoluciones latinoamericanas. Para aproximarse de manera crítica a estas distintas crisis el autor propone un desarrollo teórico que incluya un análisis integral, es decir multidisciplinario y contextual, un examen de las sociedades en un sentido amplio.

Aunado al punto anterior, el autor considera que es América Latina el ejemplo del mejor marxismo. Sin embargo, no aclara si es porque se acerca más a sus ideales, procesos o expectativas. El autor considera que experiencias como la Revolución cubana o la insurrección zapatista en México pueden ser proyectos criticados; pero son procesos histórico-sociales que, según Veraza, en Latinoamérica se han aproximado al marxismo al asumir una postura anti-capitalista, crítica pero sobretodo praxiológica. 
El marxismo de Jorge Veraza como una

reconstrucción crítica de la teoría marxista

Desde lo anterior, propone una comprensión del marxismo como no utópico. Puesto que, el autor desarrolla y da varios ejemplos históricos "fallidos"; aunque, esto no quiere decir que por ello sea utópico, pues la alternativa marxista tiene un carácter teórico y también praxiológico, características que siguen manteniendo la propuesta en potencia de realización a futuro. Con mayor razón, considerando los proyecto que si bien no se ha realizado en su totalidad, han ganado ciertas demandas en pro de los oprimidos, resultados que los acercan a un marxismo crítico realista.

Veraza resalta que las lecturas a Marx siempre vuelven o se incrementan en temporada de "crisis" y remite a casos muy concretos en América Latina con México, Bolivia y Venezuela. Experiencias que, como sostiene más atrás no se han desarrollado plenamente como marxistas; pero, ante la brutalidad de las crisis capitalistas, han buscado una alternativa en la construcción de sociedades diferentes a lo establecido por este sistema político-económico.

Veraza asevera que la teoría marxista está más cercana a una teoría practico -social que filosófica. Sin embargo si contemplamos el contexto histórico de Marx, el siglo XIX, en la cual el antecedente de las "historias filosóficas" lo tenemos en el siglo XVIII esta idea es rebatible. Además, al considerar la actividad crítica y reflexiva como características elementales del marxismo, se recurre a prácticas que también pueden marcarse dentro del ejercicio filosófico. Ejercicio que ya sea desde el marxismo o las diferentes teorías filosóficas, siguen investigando el mundo y las sociedades de hoy, para encontrar una alternativa que conduzca a la construcción de mejores y condiciones más justas para los humanos en general.

\section{Referencias}

Carr, Barry. La izquierda mexicana a través del siglo XX. México: Era, 1996. Cocheiro Bórquez, Elvira, et al. Antología del pensamiento crítico mexicano contemporáneo. Buenos Aires: CLACSO, 2015. 
Del Pino, Manuel. "Marxistas de hoy: la degradación civilizatoria y las tareas del marxismo, entrevista a Jorge Veraza". Revista Pensar desde abajo, 176, Número 04. 2015, pp. 177-200.

Dussel, Enrique. El último Marx (1863-1882) y la liberación latinoamericana. México: Siglo XXI, 1990.

Echeverría, Bolívar. Las ilusiones de la modernidad. México: UNAM/El equilibrista, 1995.

Escalante Gonzalbo, Pablo, et al. Nueva historia mínima de México. México: COLMEX. 2012.

Friedman Milton, Rose Milton. Libertad de elegir, hacía un nuevo liberalismo económico. España: Grijalbo, 1980.

Hayek Friedrich. Camino de servidumbre. Madrid: Alianza, 2009.

Hegel. "El señor y el siervo", en Fenomenología del espíritu. México: FCE, 2012.

Illades Carlos. Camaradas, Nueva historia del comunismo en México. México: FCE, 2017.

Illades Carlos. El Marxismo En México. Una Historia Intelectual, México: Taurus, 2018.

Luxemburgo, Rosa. Huelga de masas, partido y sindicato. Madrid: Fundación Federico Engels, 2010.

Marx, Carlos. Introducción a la crítica de la filosofía del derecho de Hegel. Madrid: Biblioteca nueva, 2010.

Marx, Carlos. El capital I: crítica de la economía política. México: FCE, 2012.

Marx, Carlos. Manuscritos económicos -filosóficos de 1844. México: Grijalbo, 1974.

Marx Carlos. Engels Federico. La ideología alemana, Crítica a la novísima filosofía alemana en las personas de sus representantes: Feuerbach, B. Bauer, Stirner y del socialismo alemán en las de sus diferentes profetas. Barcelona: Grijalbo, 1974.

Marx Carlos, Engels Federico. Manifiesto del Partido Comunista. Madrid: Mestas, 2007.

Novoa Portela María Pastora. Crisis económica, cuestionamiento ético al capital, en Magallón Diez María Teresa, Núñez Rodríguez Carlos Juan, Ética y Capitalismo: una mirada crítica en el siglo XXI. México: UAM, 2017. 
El marxismo de Jorge Veraza como una reconstrucción crítica de la teoría marxista

Ortega Reyna Jaime. El valor de uso en el marxismo de Bolívar Echeverría, en Ortega Reyna Jaime, Gómez Arredondo David (compiladores) Pensamiento filosófico Nuestro americano. México: UNAM/Eón, 2014, 17-40.

Ortega Reyna Jaime, Pacheco Chávez Víctor Hugo. "No cae rayo en cielo sereno: dos episodios del marxismo en México". Revista Actuel Marx/Intervenciones: Intervenciones y recepciones de Marx. Ediciones LOM, Número 21, segundo semestre. 2016, 147-163.

Popper Karl. La sociedad abierta y sus enemigos. Barcelona: Paidos, 2006.

Sánchez Vázquez, Adolfo. Entre la realidad y la utopía. México: FCE, 1999.

Sánchez Vázquez Adolfo. Etica y política. México: FCE/UNAM, 2010.

Veraza, Jorge. Para pensar la opresión y la emancipación desde la posmodernidad. Crítica a la dialéctica del amo y el esclavo en Hegel. México: Ítaca, 2005.

Veraza, Jorge. Leer el capital hoy. México: Ítaca, 2007.

Veraza, Jorge. "Lectura de El capital de Bolívar Echeverría". Revista Navegando. México. Año 8, núm. 5 junio. 2011, 15-24.

Veraza, Jorge. Leer nuestro tiempo, leer el Manifiesto. A 150 años de publicación del Manifiesto del Partido Comunista. México: İtaca, 2013.

Veraza, Jorge. "Dialéctica histórica de la superación de la crisis del marxismo". Revista Desde abajo, 176. Número 04. 2015, 201-271.

\section{Fuentes electrónicas}

Comité Clandestino Revolucionario Indígena, Comandancia General del Ejército Zapatista de Liberación Nacional. Sexta Declaración de la Selva Lacandona. México: EZLN, 2005.

Recuperado de: http://enlacezapatista.ezln.org.mx/sdsl-es/ (Consulta: 19/7/2020).

Veraza Jorge, Conferencia magistral: Marx y el marxismo del siglo XXI. México: Feria Internacional del Libro (FILPM) Minería, 2019.

Recuperado de: https://www.youtube.com/watch?v=FwKlw-_Px7o\&t=83s

(Consulta: 07/08/2020.) 